\title{
La teologia política. Un acercamiento a la teología fundamental de J. B. Metz*
}

\author{
Álvaro Mejía Góez** \\ Recibido: 2 de febrero de 2015 • Aprobado: 3 de marzo de 2015
}

\section{Resumen}

Como tarea esencial la teología fundamental debe "dar razón de la esperanza" y como elemento base, que cualquier teólogo fundamental debe asumir como punto de partida, está la Revelación. También es claro que este mensaje que la revelación nos trasmite, se ha presentado con distintos matices de acuerdo con la época y con las características históricas de cada autor. Entendemos, entonces, que el esfuerzo de la teología manualística respondió a las necesidades de su época; pero que en el devenir histórico se fue superando una manera particular de entender la revelación y el dogma; de allí se comprenden los avances que en esta disciplina se lograron a partir del Concilio Vaticano II, sobre todo por la manera de abordar el tema de la Revelación en la constitución dogmática Dei Verbum.

Palabras Clave: apologética, política, memoria, teología, sociedad.

* Este escrito es resultado de la reflexión e investigación del autor, como proceso de formación doctoral.

* Sacerdote de la Arquidiócesis de Medellín. Filósofo y Teólogo de la Universidad Pontificia Bolivariana. Magister en Teología Fundamental de la Pontificia Universidad Gregoriana de Roma. Docente de la Facultad de Teología de la Universidad Santo Tomás. Correo electrónico: alvaromejia@usantotomas.edu.co 


\title{
Political theology. An approach to fundamental theology of J. B. Metz
}

\begin{abstract}
As an essential task fundamental theology should "give reason for hope", and as a basic element, that any fundamental theologian must take as his starting point, is the Revelation. It is also clear that this message the revelation conveys, has been presented with different shades according to the time and the historical characteristics of each author. We understand, then, that the effort of manualistic theology responded to the needs of its time; but in the course of history a particular way of understanding the revelation and dogma was surpassed; from there the progress achieved in this discipline since the Second Vatican Council, especially on how to address the issue of Revelation in the Dogmatic Constitution Dei Verbum, are understood.
\end{abstract}

Keywords: Apologetics, politics, memory, theology, society.

\section{La theologie politique. Une approche a la theologie fondamentale de J. B. Metz}

\begin{abstract}
Le devoir essentiel de la théologie fondamentale est de «rendre compte de l'espérance» et comme élément de base, que tout théologien fondamental doit assumer comme point de départ, on a la Révélation. Il est clair que le message que la Révélation nous transmet, a été présenté avec des nuances différentes selon le temps et les caractéristiques historiques de chaque auteur. On comprend donc que l'effort de la théologie manualistique a répondu aux besoins de son temps ; mais dans le cours de l'histoire on a surpassé une manière particulière de comprendre la révélation et le dogme ; à partir de là on comprend les progrès accomplis dans cette discipline depuis le Concile Vatican II, en particulier grâce à la façon d'aborder la question de la Révélation dans la constitution dogmatique Dei Verbum.
\end{abstract}

Mots-clés: Apologétique, politique, mémoire, théologie, société. 
Es a partir del postconcilio donde la teología fundamental adquiere una forma más estructurada, clara y definida de su método y objeto, dando espacio a que muchos teólogos, que inclusive fueran peritos en el Concilio, elaboraran sendos manuales de teología fundamental.

En este contexto surge la necesidad de acercarnos a algunos teólogos que con su obra ayudan a entender la tarea de la teología fundamental hoy. J. B. Metz es uno de ellos. Su labor como profesor de teología dogmática y luego sus más de treinta años como docente de la fundamental, lo hacen un teólogo de obligado estudio para quienes se inician en la disciplina teológica.

Pero Metz es especial. Su teología fundamental tiene un toque distinto, novedoso, provocador. Es un Alemán hijo de la segunda guerra mundial, de gran sensibilidad por lo social; este será su punto de partida hermenéutico para dar razón de su fe, entender su labor como teólogo y vivir su fe como cristiano católico.

Su teología fundamental es arriesgada, crítica, inquietante. Toca puntos demasiado sensibles para la ortodoxia y esto le ha costado no pocas dificultades en el seno de la Iglesia jerárquica. No obstante, la reflexión de Metz es válida y seria, de una consistencia metodológica clara y de grandes repercusiones para la teología latinoamericana. Hablar de teología del mundo o teología práctica o de teología política, es hablar de J. B. Metz.

Se ha tratado de dar en este breve trabajo las líneas primarias de la teología fundamental práctica de Metz, esperando que ello sea una pequeña contribución a la búsqueda de esta tarea fundamental de la teología.

\section{Ubicación histórica del autor y su obra}

J.B. Metz nació en 1928 en Alemania. Vivió su infancia y juventud bajo la influencia de los nazis. Fue llamado a las filas del ejército finalizando la segunda guerra mundial, cuando solo tenía 16 años. Estudió teología en Innsbruck y Munich. Discípulo de K. Rahner, tiene contacto con muchos filósofos alemanes, especialmente con miembros de la escuela de Frankfurt y representantes de la teoría crítica. Durante treinta años ha ocupado la cátedra de teología fundamental en Münster.

Para Metz es importante tomar en serio los tiempos y lugares donde se vive, se cree y se hace teología. Comenta el mismo teólogo que la guerra se constituyó en la experiencia central de su vida en cuanto que ella divide en dos su manera de ver la vida, leer la historia, e inclusive, comprender su fe. Dice Metz en una entrevista publicada a manera de libro (Metz \& Wielsen, 1996), junto con un filósofo judío, que él tuvo dos fracturas en su biografía: ver sus compañeros muertos por 
un asalto y los campos de concentración en Auschwitz. Estas dos situaciones se convierten pues en centro de su pensamiento. De allí se entiende la pregunta que Metz hace a la teología: ¿Por qué la teología no ha percibido a Auschwitz? ¿Cómo desarrolla la teología este tema? Para Metz será muy importante desarrollar un lenguaje teológico que sea iluminador para los sufrientes y oprimidos.

En el campo teológico será K. Rahner el gran maestro de Metz, aunque después habrá un distanciamiento, sobre todo por el concepto de trascendencia que introdujo Rahner, que Metz considera "ahistorica" o demasiado "desconectada" con la historia. También debemos reportar que Metz gusta de leer la obra de Von Baltasar y le sigue hasta donde Baltasar "aparece demasiado místico"; allí comienza Metz a alejarse porque le parece una teología "desencarnada".

También en el campo filosófico, Metz sostiene un constante diálogo con sus contemporáneos ya que para él es muy importante hacer teología fundamental hablando con la filosofía; es necesario "de cara a los otros, dar un fundamento a la esperanza"; "el contacto con el logos extraño, distinto, es para mi una apasionada actitud fundamental" (Metz \& Wielsen, 1996). Metz ha leído e interpretado a Hegel y a Haidegger y ha tenido contacto con los filósofos alemanes. Entre ellos se encuentran: Ernst Bloch, Adorno, Horkheimer, J. Habermas, Emmanuel Lévinas. Sobre todo le interesa Haidegger por su filosofía de "ser y tiempo", que después Metz utilizará para hacer su teología de la memoria y la narración como elementos hermenéuticos de los que hablaremos más adelante.

\section{Crítica de Metz a la apologética}

Antes de hacer su propuesta de teología fundamental, Metz hace un recorrido por la historia de esta disciplina para subrayar sus carencias y dar una justificación rigurosa a su propuesta.

Constata Metz que ya desde el Nuevo Testamento se puede encontrar una apologética hecha por el mismo Jesús; también una apologética de los primeros padres de la Iglesia. Esta apologética la encuentra Metz muy positiva, muy dialogal con los sistemas del momento; fundamental para el correcto desarrollo de la doctrina cristiana. No me detendré aquí porque luego haremos una síntesis más amplia sobre "la memoria peligrosa de Jesús".

La siguiente etapa la ubica Metz en el Iluminismo. Esta apologética parte de allí para defender unas verdades; pero es demasiado controversística y no se hace otra cosa que buscar, sobre el terreno de una racionalidad ahistorica, absolutamente desligada del sujeto concreto, la posibilidad y la condición de una 
revelación en general. Esta manera de acercarse a la revelación es demasiado "meta-histórico" y no conduce a los puntos centrales de los problemas que se imponen a una teología fundamental fiel a su época.

Después la neoescolástica que tiene un carácter innegablemente regresivo; abandona los problemas de la filosofía moderna, de la forma moderna del saber y de la vida. La neoescolástica busca suelo firme y seguro en el pasado, retornando inmediatamente a tradiciones pre-modernas. En este sentido la apologética se hace polémica en sentido amplio. "El único objetivo parece ser siempre el aislamiento y la inmunización con vistas a una nueva estabilización" (Metz, 1979); dirá Metz que esto será culpable de muchas miserias teológicas y eclesiales.

En el momento que religión y sociedad se separan, gracias al iluminismo, la Iglesia busca compensar una cierta pérdida de normatividad y universalidad (Mardones, 1988)¹, a través de su "doctrina social". Así como la neoescolástica alza sus armas defensivas en torno a la dogmática para defenderla, la doctrina social de la Iglesia hace un ataque contra el desafío político del tiempo. Una vez mas la sustancia teológica y dogmática de la verdad cristiana se hace extraña de frente a lo social.

Continúa Metz con su crítica y esta vez hace notar que después de la revolución francesa, nace una corriente apologética conocida como "tradicionalismo". Esta corriente se introdujo en algunos sectores teológicos y eclesiales; en ciertos ambientes de manera teórica, en otros, acompañado también por una cierta práctica. En el campo teórico el tradicionalismo metía en duda la capacidad cognoscitiva de la razón natural y ponía el acento en la total incapacidad para encontrar un acceso propio a la idea de Dios o de la Revelación. Esta manera de hacer teología fue condenada por el Concilio Vaticano I; pero anota Metz que el tradicionalismo práctico no fue atacado por la Iglesia oficial y que se practica aún entre nosotros.

Por último, Metz evalúa la apologética de hoy y da tres juicios principales sobre ella:

Se supera en línea de principio exclusivamente o menos pronunciadamente defensivo, a comparación de la neoescolástica, en su enfrentamiento con las tradiciones filosóficas y científicas de la era moderna.

1 Debe recordarse que en la epoca del iluminismo se da una "fragmentación" de la razón y que la religión pierde el centro, que hasta el momento ocupaba, de donde partía cualquier reflexión sobre el mundo, el hombre, etc. 
En la modernidad se puede hablar de Dios y de su historia con los hombres en un sentido "responsable". Así existe una voluntad de asimilación crítica y productiva de la teología cristiana.

La apologética se convierte en teología fundamental que se ocupa de los problemas que tienen que ver con los fundamentos mismos de la fe, y no sólo de meras estrategias defensivas; este avance se debe, en parte, a la distinción que K. Rahner hace entre una teología "formal" y una "fundamental".

\section{Propuesta apologetica de Metz}

Para comprender la teología fundamental de Metz, es necesario saber que él hace entender que el iluminismo, que antes había sido atacado por la neoescolástica, ahora, en la modernidad se convierte en "lugar teológico" para hacer teología. En este lugar se puede hacer teología en tres maneras: Teología de la secularización, teología liberal y teología del mundo. Las dos primeras le parecen a Metz equivocadas, en el sentido que ambas son extremos excesivos. Paso a explicar porqué.

La teología de la secularización, según Metz, es "posible en la relación de la teología con la época moderna, porque aquí por primera vez la fe cristiana se comprende en su radical alteridad en el confrontamiento con el mundo...la fe cristiana restituye al mundo a si mismo" (Metz, 1998); pero inmediatamente Metz pregunta por la legitimidad de una visión teológica en estos términos: "Permanece, pues, problemático si una tesis tal de la secularización en su forma consiguiente, conduzca, efectivamente, a la constitución de la razón teológica en sus relaciones con la época moderna, o si no representa, por el contrario, el inicio de su disolución, es decir, la privatización de sus facultades" (Metz, 1998). Preocupa a Metz en esta teología de la secularización, que la fuerza crítica y liberante del cristianismo, que debe ejercer en la historia, permanezca esencialmente escondido ya que se hace una brecha entre mundo-sociedad y fe-cristianismo; y una teología así tiene una "predilección por la, así dicha, 'doctrina de los dos reinos'" (Metz, 1998). Para Metz esta teología "en su resuelta mundanidad no representa en el fondo otra cosa que una nueva forma de inmunización de lo cristiano, es decir, una mala apologética en el sentido más sublime de la palabra" (Metz, 1979).

La segunda manera de hacer teología del mundo, y que es equivocada para Metz, es la teología liberal. "El interés del cristianismo se hace entonces idéntico con los intereses históricamente comprensibles de la época moderna [...]" (Metz, 1998). Aquí se trata de identificar los intereses cristianos y teológicos con 
los intereses modernos. En esta teología parece que la superación del iluminismo consiste en nada menos que el triunfo del iluminismo sobre el cristianismo eclesial, o sea, en el meter el iluminismo en el puesto del cristianismo. Metz no es partidario que se haga una identificación esencial, estrecha, ontológica entre los intereses del cristianismo y los intereses de la modernidad; aspecto que es desarrollado por dicha teología liberal, especialmente en el campo protestante (Ratzinger, 1986) ${ }^{2}$.

Estas dos teologías tienen un factor común: son teologías hechas desde el iluminismo que ha creado un sujeto burgués, es decir, una persona que se reduce al ámbito privado y que por lo tanto existe aproblemáticamente en la historia. ¿Cuál es la salida? La propuesta de Metz de una teología política -escatológica se coloca como una tercera vía para hacer una correcta teología fundamental en la modernidad. Ahora tratare de dar los puntos básicos de esta teología:

Esta teología emprende el tentativo de interpretar y movilizar los contenidos transmitidos por el cristianismo como 'peligrosa memoria' de libertad, critico-liberante, en el proceso de emancipación, de la secularización y del iluminismo de la época moderna" (Ratzinger, 1986). Para Metz es muy importante la figura de Kant como uno de los filósofos que teoriza la modernidad desde su filosofía de la razón pura y la razón práctica. En los estudiosos de la modernidad y sus consecuencias se puede leer cómo la modernidad dio gran relevancia a la razón pura (Metz, 1998), una de las características, precisamente del sujeto burgués descrito por Metz; es por ello que en su teología política se dimensiona positivamente la razón práctica y se intenta hacer de esta teología un instrumento que ayude a la razón crítica a hacerse práctica. Define el mismo Metz: "La teología política es un tentativo de expresar el mensaje escatológico del cristianismo en la relación con la época moderna como figura de la razón crítico-práctica (Metz, 1998).

Para Metz es de vital importancia que el discurso sobre Dios implique un discurso sobre el sentido y sobre el sujeto de la historia entendida desde su totalidad. Aquí introduce el teólogo una categoría hermenéutica esencial: la escatología; en ella podemos entender que la historia encuentra su sentido, su cumplimiento; ella nos ayuda a entender que Dios es y será definitivamente el

2 Una crítica semejante la encontramos en la entrevista hecha al cardenal J. RATZINGER que se publicó como libro con el titulo de Informe sobre la fe. 
Señor de la historia. Esta escatología escapa a cualquier explicación que se intente hacer desde la pura razón, por esto es importante la razón práctica, ésta sí nos proporciona unas herramientas intelectuales que hacen lo escatológico "razonable" desde la misma historia y aquí entra entonces el marxismo.

No quiere Metz que se identifique su teología con el marxismo, pero si encuentra en él un "uso" adecuado de la razón practica: "En el marxismo clásico la cuestión sobre el sentido universal de la historia se mantiene vivo en su intención práctica: como contenido y como meta de la praxis revolucionaria. Este tener viva la cuestión del sujeto y del sentido de la historia global empuja sobre todo al marxismo clásico a estar vecino a la posición cristiana-teológica en el contexto de nuestra problemática" (Metz, 1998). En el momento de hacer referencia al marxismo Metz recibe no pocas críticas a lo que él responde: "Una teología que hoy haga demasiado énfasis sobre su inocencia social y política, sobre su carácter apolítico, la que afirme de ser el abogado y solo el abogado de lo 'específicamente cristiano' y de no tener por tanto nada que hacer con la praxis social y política, en fondo no es otra que una figura disfrazada de conformismo a esta solución 'idealistica' del problema de la razón práctica en la relación con la época moderna" (Metz, 1998).

Otro elemento hermenéutico que Metz introduce en su teología fundamental es el de memoria. Pero no una memoria cualquiera, es la memoria de Jesús; ella tiene unas características: es "peligrosa", orientada al futuro, anticipadora. ¿Qué significa todo esto?

Memoria y narración son categorías de la conciencia histórica que ayudan al hombre a tomar conciencia y salvación de la identidad en medio de las luchas y los riesgos históricos, en los que el sujeto se experimenta y constituye como tal. Cuando se anula el recuerdo se mata la identidad del sujeto, como sucedió a los esclavos cuando fueron desarraigados de su historia; cuando se aniquila la memoria se subyuga y se reduce a la impotencia. Es sabido que la narración mantiene viva la tradición, hay un hilo conductor en las culturas, se mantiene viva la identidad, en suma, hay conciencia histórica. Pero en la modernidad esta conciencia, parece, la tiene solo el sujeto burgués que siempre ha sido vencedor y se ha olvidado hacer memoria de los vencidos y oprimidos. Es en este sentido que la memoria de Jesús es peligrosa, porque en él cobra sentido la historia de los sufrientes y marginados.

El punto central de nuestra fe lo constituye la memoria o recuerdo del Señor crucificado en el cual se funda la promesa de la futura libertad para todos; aquí encontramos una vez más el sentido escatológico que Metz da a su teología. En 
este recuerdo cristiano encontramos una lucha contra las tendencias modernas y por eso este recuerdo se torna peligroso y liberador frente a las presiones y mecanismos de la conciencia dominante. En los relatos bíblicos de éxodo, metanóia y conversión, Metz encuentra un referente válido para apoyarse en su concepción de teología como memoria, narración y praxis. "Este es también el lugar categorial para el tentativo de la teología de defender argumentativamente el recuento de la historia de liberación de Dios en Jesucristo de frente a la historia del sufrimiento humano [...]" (Metz, 1998).

Un último elemento (seguramente hay más pero dada la limitación en la extensión requerida en un trabajo de este tipo, me he limitado a estos) es el de la praxis.

“Una teología fundamental práctica parte de la base de que son acríticos y pseudo teóricos todos aquellos ensayos que tratan de fundamentar la teología en una 'teoría pura' o en una 'reflexión absoluta'" (Metz, 1979). Partiendo de esta premisa Metz afirma su "primado de la praxis". Afirma el teólogo que la idea de Dios es de suyo una idea práctica porque este no puede ser pensado sin que este pensamiento afecte inmediatamente los intereses del sujeto que piensa a Dios. Inclusive y sobre todo en la cristología se debe entender esta dimensión de la praxis. El seguimiento de Cristo solo es entendido desde esta categoría. La praxis no toca solamente el aspecto moral del individuo sino también su aspecto social; de aquí se sigue que esta praxis toque también lo político. En este mismo sentido Metz subraya que el cristianismo no es solo un conjunto de verdades, mandamientos y ritos; sino ante todo una manera de ser en el mundo. La praxis cristiana debe ir en conexión con un principio esencial para Metz: la solidaridad.

\section{Conclusión}

A manera de conclusión quiero compartir simplemente un párrafo que encontré en una de las obras de Metz citada aquí, que intenta dar una definición de la fe fundamental de un cristiano y que recoge las categorías que en este breve trabajo he desarrollado como puntos esenciales de la teología fundamental de J.B. Metz y que pueden ser la base epistemológica de una teología crítica:

La fe de los cristianos es una praxis dentro de la historia y de la sociedad, que se concibe como esperanza solidaria en el Dios de Jesús en cuanto Dios de vivos y muertos que llama a todos a ser sujetos en su presencia (Metz, 1979). 


\section{Referencias}

Mardones. J. M. (1988). Postmodernidad y cristianismo. El desafío del fragmento. Santander: Sal Terrae.

Metz, J. B. (1979). La fe, en la historia y la sociedad. Madrid: Cristiandad, 32.

Metz, J. B. (1998). Sul concetto della nuova teologia politica. Brescia: Queriniana.

Metz, J. B. \& Wielsen, E. (1996). Esperar a pesar de todo. Madrid: Trotta.

Ratzinger, J. (1986). Informe sobre la fe. Madrid: BAC Popular. 